\title{
A Study on Infant Feeding Practices and Growth Assessment in Field Practice Area of PIMS, Karimnagar
}

\author{
Dr Praveen Kumar
}

\author{
Assistant Professor, Department of SPM, Prathima Institute of Medical Sciences, Naganoor, Karimnagar. \\ Address for correspondence: Dr. Praveen KumarS/o Bakkappa, H. No 19-1-245, Bankers Colony, Shivanagar, \\ Bidar- 585401. Karnataka state Email: drpk82@gmail.com
}

DOI:10.47799/pimr.0901.08

Date of receiving 24-01-2021

Date of peer review 10-02-2021

Date of acceptance 18-02-2021

\section{ABSTRACT:}

Background: The common cause of deaths in $50 \%$ of children below the age of 5 years is undernutrition. It is estimated that $13-16 \%$ of these deaths can be easily avoided by exclusive breastfeeding in the first 6 months. An additional $6 \%$ of deaths may be avoided by appropriate complementary feeding till the age of 2 years. We in the current study tried to evaluate the infant feeding practices in the field are of PIMS, Karimnagar.

Methods: The variables recorded were Religion, Literacy status, and socioeconomic status: Socio-economic status was recorded based on Modified Kuppuswamy Classification.Type of family, Type of House, Birth Weight, and Immunization status. A Predesigned and pre-tested proforma was used the investigator interviewed the mother in the local language using a predesigned proforma. Each infant-mother was interviewed for about 40 minutes. Sample size calculation AP prevalence of exclusive breastfeeding is 67.2 (NFHS -3), Calculation of sample size for qualitative data the total was rounded to $n=400$

Results: And all the babies were given colostrum feeding. 302 (75.4\%) of mothers had initiated breastfeeding within 2-4 hours followed by 85 (21.3\%) who were breastfed within the first one hour, 8(2\%) who were breastfed within 7-12 Hrs, 4(1\%) who were breastfed within 12-24 hrs. Weight for age, 284 (71\%) of childrenwere normal, 86 (21.5\%) were moderately underweight and 30 (7.5\%) wereseverely underweight.When length for age was assessed, 58 (14.5\%) weremoderately stunted and 24 (6\%) severely stunted. For length for weight, thepresent study observed that $87(21.75 \%)$ had moderate wasting and $43(10.75 \%)$ had severe wasting. A significant difference was noted betweenboys and girls with regards to weight for age and length for weight.
Conclusion:

The overall new-born care practices were good in the present study area. The majority (99\%) of the deliveries were conducted in institutions by a skilled birth attendant. Three fourth of the women had an interval of 25-36 months between the previous two successive deliveries. Most (94.1\%) of the new-born were wrapped immediately after birth and bathing of the new-born was delayed till 2 days (70.6\%) to avoid hypothermia. However, practices like application on the umbilical cord and giving bath to the new-born were also observed on certain occasions.

Keywords: Infant Feeding Practices, Growth Assessment, PIMS Field area Karimnagar

Introduction

Infant care and feeding practices show the importance given to thewellbeing of the new-born and raising an infant well. Infant feeding is one ofthe important functions of the family with which medical and community healthworkers are concerned. ${ }^{[1]}$ Infant care and feeding practices include thecare given during birth, feeding practices of the infant-like early initiation ofbreastfeeding, exclusive breastfeeding, and complementary feeding; and italso includes the hygiene, sleep pattern, clothing, habit training and arepassed from one generation to another.[1]Realizing the importance ofchild development. United Nations declared 1979 as the International Year ofthe Child (IYC) ${ }^{[2]}$ and World Health Organisation (WHO) proposed a theme onworld health day during 2003 as 'Healthy environment for children' and 2005as 'Make every mother and child count' to focus the attention of planners, policymakers, administrators, health and social scientists on variousproblems faced by children.[3]Several recent global meetings have increased awareness of theunmet health needs of children. The United Nations established 
eightMillennium Development Goals (MDGs) in September 2000, which isdesigned to provide a framework for measuring development progress.Although advancements on all eight MDGs are important to the survival andwellbeing of children, MDG 1 and MDG 4 have targets that directly affectchildren's health. In MDG 1, indicator 4 denotes the prevalence of underweightchildren under three years of age; it should be halved between 1990 and2015. MDG 4 mainly focus to reduce child mortality, indicators 13,14, and 15are under-five mortality rate, infant mortality rate, and proportion of infants notimmunized against measles. ${ }^{[4]}$ The mortality rate in children in India below five years is 59 per 1,000 livebirths. Around 56\% of under-five deaths occur in the first month of life, and a totalof $79 \%$ of under-five deaths occur during infancy including the neonatal period. Arural-urban differential in under-five mortality is evident and stands at 28points. ${ }^{\left[{ }^{[4]}\right.}$ However, the encouraging trend is that the decline in rural childmortality has been faster than the urban. There is also a gender differential of9 points in the under-five category (female:64; male:55), underlining theneed to address social determinants of health, including the status of womenand the girl child, female literacy, and women's economic and socialempowerment. ${ }^{[5]}$ Several programs have been implemented by the Government of Indiaalong with WHO and UNICEF to improve the health status of infants. Manycustoms are prevalent in India which affects the health status of infants. Understanding the community and traditional infant care and feedingpractices is necessary to implement an effective program for the promotion ofnew-borns and infant's health.

\section{Material and methods}

This cross-sectional study was conducted in the field practice area of PIMS, Karimnagar. Ethical clearance for the study was obtained from Institutional Ethical Committee.In the rural health training centerVutoor of Prathima Institute of MedicalSciences, Karimnagar, there are four villages.1) Vutoor sub-center has two villages (Govt) a) Vutoor, b)Vegurupally,2) Pachunur Sub-center has two villages (Govt) a) Pachunur, b)Maddikunta. The variables recorded wereReligion, Literacy status, Socioeconomic status: Socio-economic status was recorded based on Modified Kuppuswamy Classification.[6] Type of family, Type of House, Birth Weight, and Immunization status. A Pre-designed and pre-tested proforma was used the investigator interviewed the mother in the local language using a predesigned proforma. Each infant-mother was interviewed for about 40 minutes. Sample size calculation AP prevalence of exclusive breastfeeding is 67.2 (NFHS -3), Calculation of sample size for qualitative data the total was rounded to $n=400$

\section{Inclusion Criteria}

1. All children from the age group of $12-24$ months were included.

\section{With consent residents.}

\section{Exclusion Criteria}

1. Children with congenital malformations.

2. Not given consent.

3. Non-residents.

Anthropometric measurements:Length: The infant was placed on the infantometer with his back on the horizontalplane surface and his/her shoulders and buttocks were flat against themeasuring surface. Making the infant's head in an upright position with both legsin the fully extended position and the toes pointing upwards with feet flat againstthe flexible end of the infantometer, the length was measured to the nearest0.1 $\mathrm{cm}$.Weight:- The body weights of the infant were measured to the nearest 0.1 kgusing a salter scale with the help of anganwadi worker. Each infant was placedwith minimum clothing. It was ensured that the infantlied freely without touching any object and the weight was recorded.Head circumference: Head circumference was measured using non-stretchable plastics tape. Head circumference was measured over the mostprominent part of the occipital region and just above the supraorbitalridges. Itwas measured to the nearest $0.1 \mathrm{~cm}$. Chest circumference: Chest circumference was measured using nonstretchable plastic tape. The tape was placed firmly around the chest at thelevel of the nipple and was measured to the nearest $0.1 \mathrm{~cm}$.All the measurements were recorded thrice, and the average value was takenas the final reading.The nutritional status of the infant was calculated by height for age, weight for ageweight for height using WHO data as the reference point.[7]The value of median - 2 SD was taken as the cut-off point for detection ofwasting, stunting, and undernutrition.A total of 400 children in the age group of 12 to 24 months were enrolled from rural health training center area Vutoor, Karimnagar.The data was entered and analyzed using Microsoft Excel. Data werepresented as percentages and ratios. To find out the association between infantcare and rearing practices with socio-demographic characteristics and feedingpractices, the Chi-square test, and Fisher's exact $p$ test were used. Median wascalculated for anthropometric measurements. Fisher's exact $p$ test was used when at least one expected value was lessthan one or $20 \%$ of values were less than five.p-value $<0.05$ was considered as statistically significant.Statistical data were analyzed with the help of Excel functions, StatisticalPackage for Social Sciences, (SPSS Version 21). 


\section{Results}

Out of the total $n=400$ mothers, majority $n=280(70 \%)$ were in the age group of $20-25$ years age group followed by $88(22 \%)$ in $<20$ years age group, $24(6 \%)$ in26-30 years age group, 08 $(2 \%)$ in $>30$ years age group, Mean age of themothers was 22.54 and standard deviation (SD) was 2.58 (table 1).

Table 1: Age-wise distribution of the mothers

\begin{tabular}{|l|c|c|}
\hline Age group & Number & Percentage \\
\hline$<20$ & 88 & 22 \\
\hline $20-25$ & 280 & 70 \\
\hline $26-30$ & 24 & 6 \\
\hline$>30$ & 08 & 2 \\
\hline Total & 400 & 100 \\
\hline
\end{tabular}

Almost three-fourths $328(82 \%)$ were from a joint family and the rest $72(18 \%)$ were from a nuclear family. The majority 208 (52.0\%) had education up to high school followed by 108 (27\%) studied up to intermediate, $24(6 \%)$ studied up to Middle School, 20 (5\%) were graduates and above, 12 (3\%) studied up to Primary School, Above $28(7 \%)$ were illiterates. Out of the total 400 mothers, majority $368(92 \%)$ were homemakers byoccupation, $16(4 \%)$ were unskilled workers, $8(2 \%)$ were semiskilled workers, $4(1 \%)$ were skilled workers, $4(1 \%)$ were clerical, Shop owners and farmers (Table 2).

Table 2: Occupation of the mothers

\begin{tabular}{|l|c|c|}
\hline Occupation & Number & Percentage \\
\hline Unemployed & 368 & 92 \\
\hline Unskilled worker & 16 & 4 \\
\hline Semi-skilled worker & 8 & 2 \\
\hline Skilled & 4 & 1 \\
\hline Clerical, Shop owner, Farmer & 4 & 1 \\
\hline Total & 400 & 100 \\
\hline
\end{tabular}

The majority 252 (63.0\%) belonged to the upper-middle (class II) followed by $128(32.0 \%)$ lower-middle (class III), 20 (5\%) upper-lower (class-IV) based onmodified Kuppuswamy SocioEconomic Status. The majority of the mothers 316 (79\%) had 6 antenatal visits during pregnancy followed by $56(14 \%)$, had 5 antenatal visits, $8(2 \%)$ had 7 antenatal visits, $8(2 \%)$ had 9 antenatal visits, $4(1 \%)$ had 8 antenatal visits during pregnancy. About two-thirds (61\%) had normal delivery followed by 144 $(36 \%)$ cesarean section and the rest had forceps delivery (3\%).About $98.0 \%$ of the deliveries were institutional, among whic 14 the majority 284 (71.0\%) were done in a private hospital, $108(27 \%)$ were done in a Government hospital, 8(2\%) were done in the Home. Health care personnel conducted delivery in the majority (99\%) of the majority. 4

(1\%) were delivered by an untrained dai.Except for $4(1 \%)$ mothers, rest all 396 (99\%) were advised about the importance of breastfeeding during their antenatal visits by the health care providers.

Table 3: Distribution of mothers according to their counseling aboutbreastfeeding during antenatal visits

\begin{tabular}{|l|c|c|}
\hline $\begin{array}{l}\text { Advice about breastfeedingduring } \\
\text { antenatal visits }\end{array}$ & Number & Percentage \\
\hline Advised & 396 & $99 \%$ \\
\hline Not advised & 4 & $1 \%$ \\
\hline Total & 400 & 100 \\
\hline
\end{tabular}

$\mathrm{N}=300(75 \%)$ were in the $1-1 \frac{1}{2}$ years age group followed by $100(25 \%)$ who were more than $1 \frac{1}{2}-2$ years ago. Sex wise distribution showed that 252 were males and 148 females. In the present study majority of $400(100 \%)$ were given breastfeeding. And all the babies were given colostrum feeding. 302 (75.4\%) of mothers had initiated breastfeeding within 2-4 hours followed by 85 (21.3\%) who were breastfed within the first one hour, $8(2 \%)$ who were breastfed within $7-12 \mathrm{Hrs}, 4(1 \%)$ who were breastfed within $12-24 \mathrm{hrs}, 1(0.3 \%)$ who were breastfed within 4-6 hrs. The main reason for the delay in the initiation of Breast Feeding was due to the baby's illness. N=396 (99\%) did not give any pre-lacteal feeds before the initiation of breast feeding. Sugar water was the most common prelacteal feed that was given to the new-born. Demand feeding was seen in the majority 372 (93\%), $28(7 \%)$ in regular intervals. 
Table 4: Age and sex-wise distribution of the children

\begin{tabular}{|l|c|c|c|c|c|c|}
\hline \multirow{2}{*}{ Age (years) } & \multicolumn{2}{|c|}{ Male } & \multicolumn{2}{c|}{ Female } & \multicolumn{2}{c|}{ Total } \\
\cline { 2 - 7 } & Number & Percentage & Number & Percentage & Number & Percentage \\
\hline $1-11 / 2$ & 204 & 81 & 96 & 64.9 & 300 & 75 \\
\hline $11 / 2-2$ & 48 & 33.3 & 52 & 35.1 & 100 & 25 \\
\hline Total & 252 & 100 & 148 & 100 & 400 & 100 \\
\hline
\end{tabular}

Among the total study population, exclusive breastfeeding for six months waspracticed by 256 (64\%) of the mothers. In 144 (36\%) exclusive breastfeedingwas practiced for more than 6 months (table 5). $\mathrm{N}=20$ (5\%) mothers discontinued breastfeeding within one year and 336 (84\%) at 1-2 years, $44(11 \%)$ discontinued breastfeeding within $2-3$ years. The most common reason for the cessation of breastfeeding was to encourage children to eat solid foods 352 (88.0\%). Other reasons cited were cessation of milk $8(2 \%)$, return to work 16 (4\%), next pregnancy $24(6 \%)$.

Table 5: Distribution according to the pattern of exclusive breastfeeding

\begin{tabular}{|l|c|c|}
\hline $\begin{array}{l}\text { Exclusive breastfeeding for } \\
6 \text { months }\end{array}$ & Number & Percentage \\
\hline <6MONTHS & 256 & $64 \%$ \\
\hline$>6$ MONTHS & 144 & $36 \%$ \\
\hline Total & 400 & 100 \\
\hline
\end{tabular}

Only $48(12 \%)$ were started on weaning foods at the sixth month of age. About348 (87\%) were started weaning foods after six months of age, $4(1 \%)$ werestarted on wearing foods within 6 months of age. 373 (93.3\%) were receiving artificial feeding. The most common reason for artificial feeding was inadequate breast milk 304(76\%) followed by convenience 92 (23.0\%), another pregnancy $4(1 \%)$. Buffalo's milk was the common type of artificial feed given 316 (79\%),followed by cow's milk 72 (18\%), Tinned Milk power 12 (3\%). a common source of information regarding artificial feeding was healthpersonnel 308 (77\%) followed by family members 52 $(13 \%)$, peer groups $28(7 \%)$, Mass media $12(3 \%)$. The majority of the children 336 (84.0\%) were fully immunized and 64 (16\%) were partially immunized.The nutritional status of the children was assessed by using the WHO z-score asa reference value (Table 6). With regards to the weight for age, 284 (71\%) of childrenwere normal, 86 (21.5\%) were moderately underweight and 30 (7.5\%) wereseverely underweight. When length for age was assessed, 58 (14.5\%) weremoderately stunted and $24(6 \%)$ severely stunted. For length for weight, thepresent study observed that 87 (21.75\%) had moderate wasting and $43(10.75 \%)$ had severe wasting. A significant difference was noted betweenboys and girls with regards to weight for age and length for the weight $(p<0.05)$.

Table 6: Nutritional Status of the Study Children

\begin{tabular}{|l|c|c|c|c|}
\hline Variable & $\begin{array}{c}\text { Boys } \\
(\mathrm{n}=252)\end{array}$ & $\begin{array}{c}\text { Girls } \\
(\mathrm{n}=148)\end{array}$ & $\begin{array}{c}\text { Total } \\
(\mathrm{n}=400)\end{array}$ & P-value \\
\hline Weight for age & 169 & 115 & $284(71 \%)$ & \\
Normal & 67 & 19 & $86(21.5 \%)$ & 0.0005 \\
Moderate underweight & 17 & 13 & $30(7.5 \%)$ & \\
Severe Underweight & 189 & 129 & $318(79.5 \%)$ & \\
\hline Length for age & 45 & 13 & $58(14.5 \%)$ & 0.014 \\
Normal & 18 & 6 & $24(6 \%)$ & \\
Moderately stunted & & & \\
Severe stunted & &
\end{tabular}




\begin{tabular}{|l|c|c|c|c|}
\hline Length for weight & 146 & 121 & $267(66.75 \%)$ & \\
Normal & 73 & 14 & $87(21.75 \%)$ & 0.000 \\
Moderate wasting & 30 & 13 & $43(10.75 \%)$ & \\
Severe wasting & & & & \\
\hline
\end{tabular}

\section{Discussion}

The present study aimed at assessing infant feeding practices and growthassessment in the field practice area of Prathima Institute of MedicalSciences, Karimnagar. Early initiation of breastfeeding, exclusivebreastfeeding for six months, and timely introduction of age-appropriatecomplementary feeding are the key interventions to the child survival andproper development of the child.The majority of the mothers in the study were in the age group of 20-25 years witha mean of 22.54 \pm 2.58 . About three-fourths were from joint family. About 28 (7\%) were illiterates andthe majority 208 (52\%) had education upto high school. The majority werehomemakers by occupation and the majority 252 (63\%) belonged to the uppermiddle(Class II).A Study by Sanjay V Wagh et al; ${ }^{[8]}$ observed that the age of lactating mothers ranged between 18-35 years. 126 (51.21\%) were between the age group 24-29 years. Most of the mothers belong to the nuclear family, i.e. 153 (62.20\%), Majority 123 (50\%) had education upto secondary level whereas only 21 (8.5\%) were illiterate. Out of a total 192 (78.04\%) had delivered in a government hospital. Another study by K. Madhu et al; [9] found that most of the mothers were between the ages of 21 and 25 years old (60\%) and 15 and 20 years old (30\%). About $52 \%$ of the mothers were illiterate and belonged to a low to medium socio-economic class (55\%). Approximately $11 \%$ of the mothers were housewives (69\%) and mothers who were employed were $22 \%$.Prelacteal feeding a very common practice in India; data indicate that mothers delay breastfeeding for several hours to avoid giving colostrums and supplement breastfeeding with other foods or liquids. But in contrast to the previous observations, the present study observed that only $1 \%$ of the new-born were given pre-lacteal feeds. Sugar water was the common pre-lacteal feed that was given to the new-borns in India. ${ }^{[10-13]}$ According to Infant and Young Child Feeding Practices (2006) guidelines inIndia, ${ }^{[14]}$ it is recommended that initiation of breastfeeding should begin immediately after birth and exclusive breastfeeding should be given for six months. The early introduction of complementary feeding increases the risk of infection in the infant. In the present study, the majority (100\%) were given breastfeeding and the majority $(75.4 \%)$ initiated breastfeeding within 2-4 hours. The main reason for the delay was the baby's illness. A similar kind of results was observed in studies by Madhu K et al; ${ }^{[15]}$. IMNCI recommends on-demand breastfeeding or feeding 8 times or beyondto the new-born. Demand feeding was seen in $94 \%$ in the present study.The nutritional status of the children was assessed by using the WHO z-score as the reference value. With regards to the weight for age, 86 (21.5\%) were moderately underweight and $20(5 \%)$ were severely underweight. When length for age was assessed, 55 (13.7\%) were moderately stunted and $15(3.7 \%)$ severely stunted. For length for weight, the present study observed that 96 (24\%) had moderate wasting and $43(10.7 \%)$ had severe wasting. Sudarsan Mandal et al; ${ }^{[14]}$ in Kolkata found that theoverall prevalence of under-nutrition among the study population was found tobe 54 (45\%). Among infants 9 (25\%) were underweight, $3(8.3 \%)$ werestunted, 22 (61.1\%) were wasted and 23 (63.9\%) showed thinness.

\section{Conclusion}

The overall new-born care practices were good in the present studyarea. The majority (99\%) of the deliveries were conducted in institutions by askilled birth attendant. Three fourth of the women had an interval of 25-36months between the previous two successive deliveries. Most (94.1\%) of thenew-born were wrapped immediately after birth and bathing of the newbornwas delayed till 2 days (70.6\%) to avoid hypothermia. However, practices likeapplication on the umbilical cord and giving bath to the new-born were alsoobserved on certain occasions.

Limitation: Single time assessment will not reveal the overall actual health and nutrition status of the child; it needs a regular follow and repeated observation over different periods. Hence efforts should be made for health, infant feeding practices, and growth assessment at regular intervals.

\section{REFERENCES}

1. Park K. Park's Textbook of Preventive and Social Medicine. 22nded, Jabalpur: BanarsidasBhanot; 2013: 636.

2. UNICEF. Year of the child. New York: UNICEF [online]; 1979 Available from: http://www.unicef.org/about/history/ files/Child-Nation-M-Black-Ch15-p353-377-year-orchild.pdf [Accessed on 12/09/2020]

3. World Health Organization. The World Health Day themes. Geneva: WHO [online]. 2013 Available from: http:// www.who.int/world-health-day/previous/en/[Accessed on $11 / 11 / 2020]$

4. Government of India. Millennium Development Goals India country report 2011. New Delhi: Central Statistical Organisation, GOI [online]. 2011 Available from: URL: http://www.mospi.nic.in. [Accessed on 12/10/2020].

5. Sample Registration System. SRS Bulletin: Census and Vital Statistics. India: Ministry of Home Affairs, GOI [online]. 
Sep 2013 Available from: URL: http://www.censusindia. gov.in[Accessed on 01/12/2020].

6. Kumar N, Gupta N, Kishore J. Kuppuswamy's socioeconomic scale: Updating income ranges for the year 2012. Indian J Public Health 2012;56:103-4

7. World Health Organization. The WHO child growth standards. Geneva: WHO [online]. 2010 [cited 2013 June 24]. Available from: URL:http://www.who.int/ childgrowth/standards/en/[Accessed on 11/12/2020].

8. Sanjay V Wagh, Santoshi S Wagh, Mohan M Raut, Dharampal G Dambhare, Diwakar A Sharma.Study of Breast-Feeding Practices in Vidarbha Region of Maharashtra, India. Innovative Journal of Medical and Health Science 2013; 3(5):238 - 241.

9. Madhu K, Chowdary S, Masthi R. Breast feeding practices and newborn care in rural areas: A descriptive crosssectional study. Indian J Community Med 2009;34:24346.

10. Hiremath B R, Sorganvi V. A Cross-Sectional Study on Breastfeeding Practices In A Rural Area Of North Karnataka. IJCRR. 2013; 5(21): 13-18.

11. Bindu A, Noushadali A. K, Kutty P. M.Knowledge, attitude, and practice of breast feeding mothers in a tertiary care centre: a descriptive study. Int J Pediatr Res. 2017;4(12):706-712.

12. Shashank K J and Chethan TK. A study of breastfeeding practices among mothers in rural area of Mangalore district: A cross-sectional study. National Journal of Community Medicine. 2016;7(2):134-137.

13. Ministry of Women and Child Development (Food and Nutrition Board) Government of India 2006. Available from www.motherchildnutrition.org [Assessed on 12/12/ 2020]

14. S Mandal, Ram Prahakar V, j Pal, R Parthasarthi, Rahul B. An assessment of nutritional status of children aged 0-14 years in a slum area of Kolkata. International Journal of Medicine and Public Health 2014;4(2):162-64.

How to cite this article : Praveen Kumar. A Study on Infant Feeding Practices and Growth Assessment in Field Practice Area of PIMS, Karimnagar.Perspectives in Medical Research 2021; 9 (1): 37-42

DOI:10.47799/pimr.0901.08

Sources of Support: Nil, Conflict of interest: None declared 